\title{
Effect of eradication of the Oriental fruit fly, Bactrocera dorsalis, on the population density of the melon fly, Bactrocera cucurbitae, in the Ryukyu Archipelago, estimated from the number of male flies captured by attractant traps
}

\author{
Yosiaki ITô* \\ 2-2908, Kaguyama, Nisshin, Aichi 470-0134, Japan
}

(Received 11 March 2005; Accepted 19 July 2005)

\begin{abstract}
The effect of eradication of the Oriental Fruit Fly, Bactrocera dorsalis, on the density of the Melon Fly, Bactrocera cucurbitae, was examined using data for the numbers of flies caught by monitor traps on islands and island groups of the Ryukyu Archipelago. A positive correlation was found between annual mean densities of $B$. cucurbitae and the number of years after eradication of $B$. dorsalis in three of four localities. Thus the density of $B$. cucurbitae seems to increase after eradication of $B$. dorsalis. This result suggests the possible effect of interspecific competition on islands where the two species coexist, but the effect is considered to be not very great. The density of $B$. dorsalis after eradication of B. cucurbitae seems to be not so different from the density on other islands where $B$. cucurbitae still exists. Attempts to eradicate a single species from localities where B. cucurbitae and B. dorsalis coexist can be planned, with careful examination of the density of a different species, as we did in the Ryukyu Archipelago.
\end{abstract}

Key words: Bactrocera cucurbitae; Bactrocera dorsalis; interspecific competition; eradication

\section{INTRODUCTION}

Many discussions have been carried out on the interspecific competition between closely related species, when both require similar resources. Although the role of interspecific competition had been strongly emphasized in many ecological textbooks during the early part of the 20th century, many ecologists (e.g. Strong, 1982; Strong et al., 1984) now consider that the effect of interspecific competition is not strong among herbivorous insects, in which populations are mainly suppressed to low densities by strong predation pressure and other factors, and this may enable coexistence of closely related insect species in the same habitat.

The Oriental Fruit Fly, Bactrocera dorsalis (Bd, hereafter), and the Melon Fly, B. cucurbitae (Bc, hereafter), are closely related species, both attacking fruits of many tropical trees, herbs and vegetables. Although the larvae of $\mathrm{Bd}$ are not seen on some cucurbit plants such as pumpkins and the bitter cucumber and those of $\mathrm{Bc}$ are not seen on many orange species, both species coexist on many tropical fruit trees such as mango and papaya, fruit vegetables such as cucumber and tomato, and many wild cucurbit plants (Ushio, 1981).

$\mathrm{Bd}$ is an introduced insect pest, which became established in the Ryukyu Archipelago (including the four island groups of Amami, Okinawa, Miyako and Yaeyama) before 1919. Bc is also an introduced species, established on the Yaeyama and the Miyako Islands before 1930, and then its distribution range expanded to the middle and northern Ryukyu Archipelago (Okinawa and Amami Islands) during the period from 1970 to 1974 (Itô and Koyama, 1982; Itô et al., 2003). Thus, both species became coexistent in all parts of the Ryukyu Archipelago after the latter half of the 1970s.

The national government of Japan provided initiatives to eradicate these introduced insect pests. For Bd, aerial distribution of fiber boards including methyl-eugenol (ME; male attractant) and insecticide were used. The attractiveness of ME is quite

*E-mail: itoyos@sam.hi-ho.ne.jp

DOI: 10.1303/aez.2005.625 
Table 1. Years of eradication of the Oriental Fruit Fly, Bactrocera dorsalis, and the Melon Fly, B. cucurbitae, from nine localities of the Ryukyu Archipelago

\begin{tabular}{|c|c|c|c|c|}
\hline Locality & $\begin{array}{l}\text { Beginning of } \\
\text { distribution of } \\
\text { ME boards }{ }^{\mathrm{a}}\end{array}$ & $\begin{array}{l}\text { Eradication of } \\
\text { B. dorsalis }\end{array}$ & $\begin{array}{l}\text { Beginning of } \\
\text { mass-release } \\
\text { of sterile flies }\end{array}$ & $\begin{array}{l}\text { Eradication of } \\
\text { B. } \text { cucurbitae }^{\mathrm{b}}\end{array}$ \\
\hline Kikai-Zima $^{\mathrm{d}}$ & 1968 & 1975 & 1981 (1974) & 1983 \\
\hline Amami-Ôsima $^{\mathrm{d}}$ & 1973 & 1975 & 1984 (1974) & 1987 \\
\hline Tokunosima $^{\mathrm{d}}$ & 1972 & 1977 & 1986 (1974) & 1989 \\
\hline Okinoerabu-Zima $^{\mathrm{d}}$ & 1970 & 1977 & 1986 (1973) & 1989 \\
\hline Yoron-Zima $^{\mathrm{d}}$ & 1970 & 1977 & $1986 \quad(1972)$ & 1989 \\
\hline Kume-Zima & 1977 & 1979 & $1974 \quad(1970)$ & 1977 \\
\hline Okinawa Islands ${ }^{\mathrm{e}}$ & 1979 & 1980 & $1986 \quad(1972)$ & 1990 \\
\hline Miyako Islands & 1982 & 1983 & $1984 \quad$ (1929) & 1987 \\
\hline Yaeyama Islands & 1982 & 1984 & $1990 \quad$ (1919) & 1993 \\
\hline
\end{tabular}

${ }^{a}$ ME: Methyl-eugenol (attracts males of B. dorsalis). Fiber boards including ME and insecticide were distributed (mainly from helicopters) for male annihilation technique to eradicate $B$. dorsalis. On some islands, short-cut ropes including ME and insecticide were distributed initially, but, as this method was not suitable, it was changed later to the distribution of fiber boards.

${ }^{\mathrm{b}}$ Years when zero-counts continued for several months are defined as the years of eradication. This is sometimes $1-2 \mathrm{yr}$ earlier than statements of 'Eradication' by the Ministry of Agriculture and Fishery, Japanese Government.

${ }^{c}$ Although the distribution of ropes including cue-lure (attractant of B. cucuribae males) was carried out to decrease the density of wild males, for several months before the sterile fly release, years at the beginning of sterile fly release are shown here. Years in parentheses show years of invasion of the Melon Fly to each locality.

${ }^{\mathrm{d}}$ The project to eradicate $B$. dorsalis from the Amami Islands began from the early 1970's, but eradication was not achieved before 1975, due to immigration of flies from southern islands (Iwahashi et al., 1976).

${ }^{\mathrm{e}}$ Except Kume-Zima (usually included to Okinawa Islands). Although the Daitô Islands (Minami- and Kita-Daitô-Zima) are not included in the Ryukyu Archipelago, they are included here as part of the Okinawa Islands.

strong for Bd, and distribution of ME-fiber boards can completely annihilate wild males, bringing rapid eradication of this species. For Bc, sterile insect release was used. Although the density of wild $\mathrm{Bc}$ males was suppressed by the distribution of fiber boards, including cue-lure (CL: attractant of $\mathrm{Bc}$ males) and insecticide, before the beginning of sterile insect release, the attractiveness of CLboards was not strong, and the main method for eradication of $\mathrm{Bc}$ was the sterile insect release. Both projects were successful, and now Japan is free from both insect pests (see Itô et al., 2003). Except Kume-Zima (Kume Island) where Bc was eradicated first, eradication of $\mathrm{Bd}$ preceded the eradication of $\mathrm{Bc}$ (Table 1).

Although Hawaii has three important species of fruit flies, Bd, Bc and the Mediterranean Fruit Fly (med-fly), distribution of the med-fly was, at the early stage of introduction, limited to highland and coffee plantations, in which the density of Bd was low. Christensen and Foote (1960) considered that this is due to interspecific competition between $\mathrm{Bd}$ and the med-fly. They also considered that the absence of the med-fly in Southeast Asia might be due to competition with other fruit fly species, mainly the Bactrocera species including $\mathrm{Bd}$ and Bc. If interspecific competition is important in determining the density or existence/absence of fruit flies in an area, eradication of a single species among coexisting species from the area may allow an increase in the density of other species in the same area.

\section{MATERIALS AND METHODS}

To estimate the relationship between the two species, data on changes in the densities of $\mathrm{Bc}$ and $\mathrm{Bd}$ accumulated by the Okinawa and Kagoshima prefectural governments were examined. For Kume-Zima (where Bc was eradicated by the sterile insect technique, carried out from 1973 to 1978 , before the beginning of the eradication project for $\mathrm{Bd}$ ), data on the density of Bd before 1973 are absent.

Divisions of Agriculture and Forestry of both prefectures accumulated tables showing number of flies caught by monitor traps (ME-traps for Bd and CL-traps for $\mathrm{Bc}$ ), for all villages, towns and cities. 
For many years, the relative numbers of flies, that is, numbers per 1,000 traps/d, are described in these tables, and I used these values for this paper. If such a relative number was not described in the original table, I calculated this by using the total number of flies caught and number of traps used in all villages, towns and cities during each month. To examine the density change in $\mathrm{Bc}$, data of densities before the beginning of distribution of CL-fiber boards were used.

\section{RESULTS AND DISCUSSION}

In common maps used by primary schools and government offices, the area named "Okinawa Islands" includes Okinawa-Hontô (main island of Okinawa), islets around Okinawa-Hontô, KumeZima and Minami- and Kita-Daitô-Zima, although Daitô-Zima's are oceanic islands not belonging to the Ryukyu Archipelago. In this area, the eradication project for Bd began in October, 1977, at first by the distribution of short cotton-strings including $\mathrm{ME}$ and insecticide. But as the cotton strings were known to attract a smaller number of Bd than MEfibre boards (Nakamori and Soemori, 1981), the distribution of ME-fibre boards was applied after the beginning of 1979 . Figure 1 (top) shows changes in the log-densities of $\mathrm{Bd}$ and $\mathrm{Bc}$ on the

OKINAWA ISLANDS

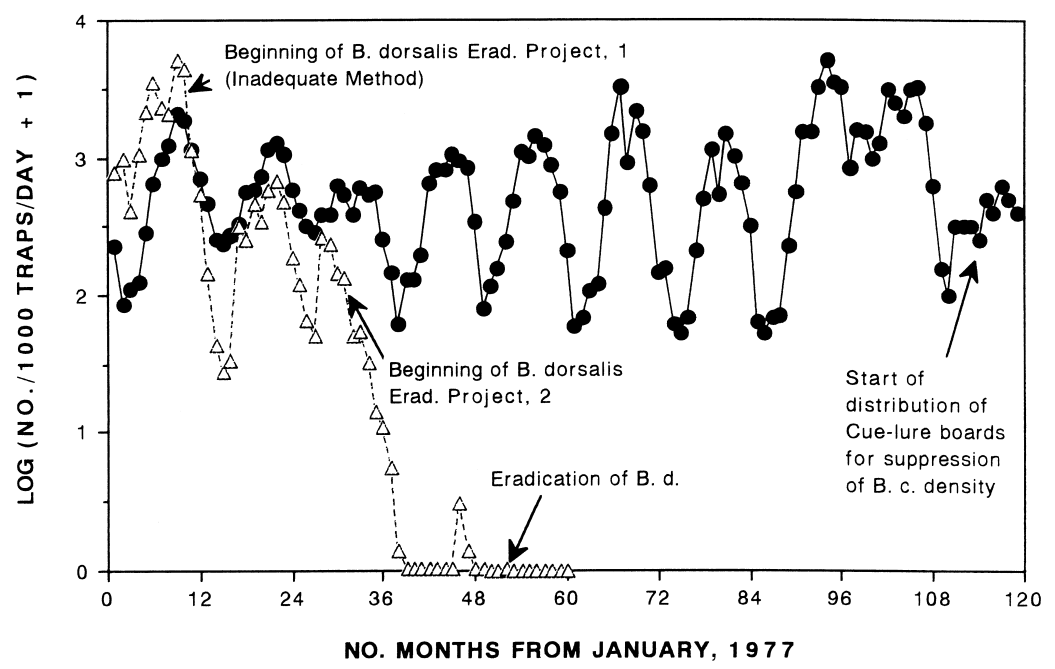

YAEYAMA ISLANDS

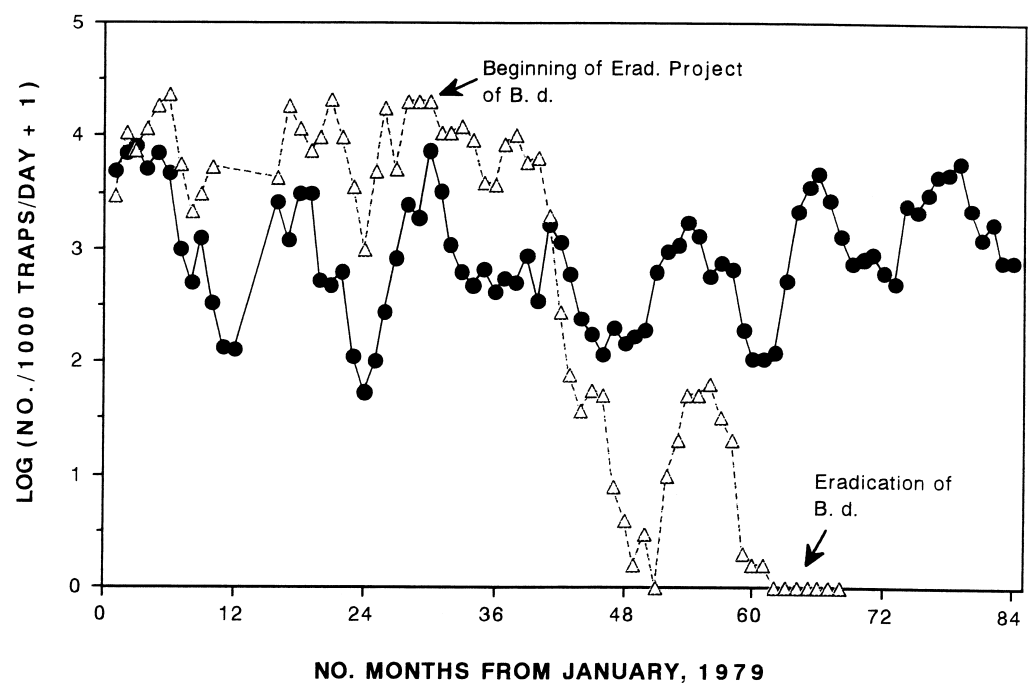

Fig. 1. Changes in numbers of Bactrocera cucurbitae (circles) and B. dorsalis (triangles), caught per 1,000 traps/d, on the Okinawa Islands (top) and Yaeyama Islands (bottom). 
Okinawa Islands excluding Kume-Zima. The actual density of $\mathrm{Bc}$ rose in late summer and declined to a minimum in the winter, every year, but peak densities differed greatly among years. As the graphs of log-density gave a better indication of the density trend, only log-density graphs are shown for all the island groups. Although $\mathrm{Bc}$ density appears to show a slight increase after the eradication of $\mathrm{Bd}$, the difference is not large (note that densities in winter of 1978 and 79 were higher than those in years after the eradication of $\mathrm{Bd}$ ).

Figure 1 (bottom) shows the log-densities of $\mathrm{Bd}$ and $\mathrm{Bc}$ on the Yaeyama Islands. The yearly maximum of $\mathrm{Bc}$ does not appear to change before or after the eradication of $\mathrm{Bd}$, but levels of annual minimum density after eradication seem to be somewhat higher than those before the eradication of $\mathrm{Bd}$.
On the Miyako Islands, we have no data on this problem, because the eradication project for $\mathrm{Bc}$ began in the year just after the eradication of $\mathrm{Bd}$.

On the Amami Islands, the invasion of $\mathrm{Bc}$ took place in 1973, $3 \mathrm{yr}$ before the eradication of $\mathrm{Bd}$. Therefore we only have data for a single year of $\mathrm{Bc}$ density before the eradication of Bd. But for reference, the data of Yoron-Zima and OkinoerabuZima are shown in Fig. 2.

Figure 3 shows changes of annual mean density of $\mathrm{Bc}$ (mean of numbers of $\mathrm{Bc}$ caught per $1,000 \mathrm{traps} / \mathrm{d}$ for $12 \mathrm{mo}$ ) during years before and after eradication of $\mathrm{Bd}$ on the Okinawa and Yaeyama islands (top) and Okinoerabu-Zima and Yoron-Zima (bottom). The density of Bc seems to increase after the eradication of Bd. Significant (5\% level) positive correlation was seen in three of four island groups (Okinawa, Okinoerabu and
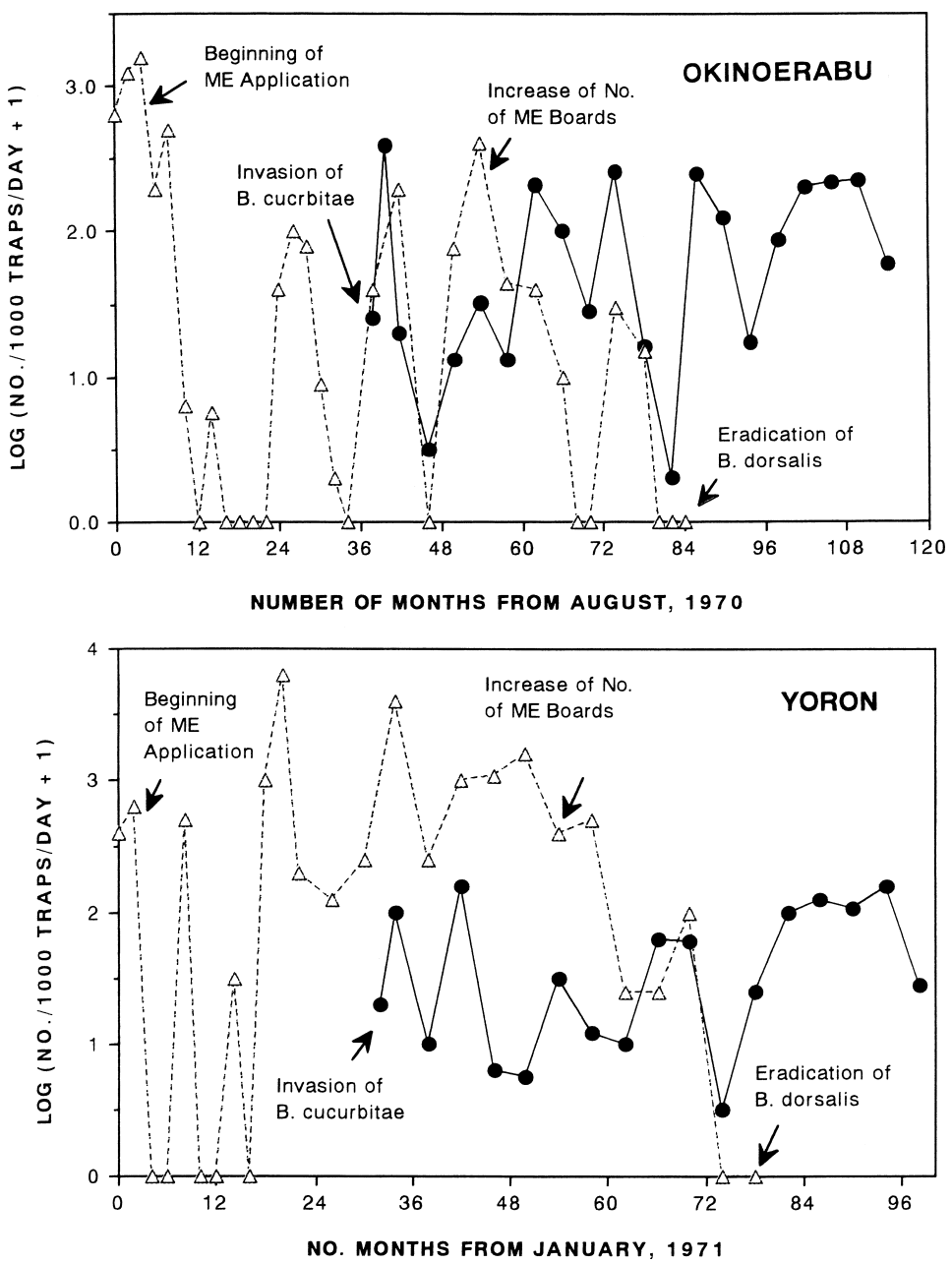

Fig. 2. Changes in numbers of two fruit fly species on Okinoerabu-Zima (top) and Yoron-Zima (bottom). For an explanation of symbols, see Fig. 1. 


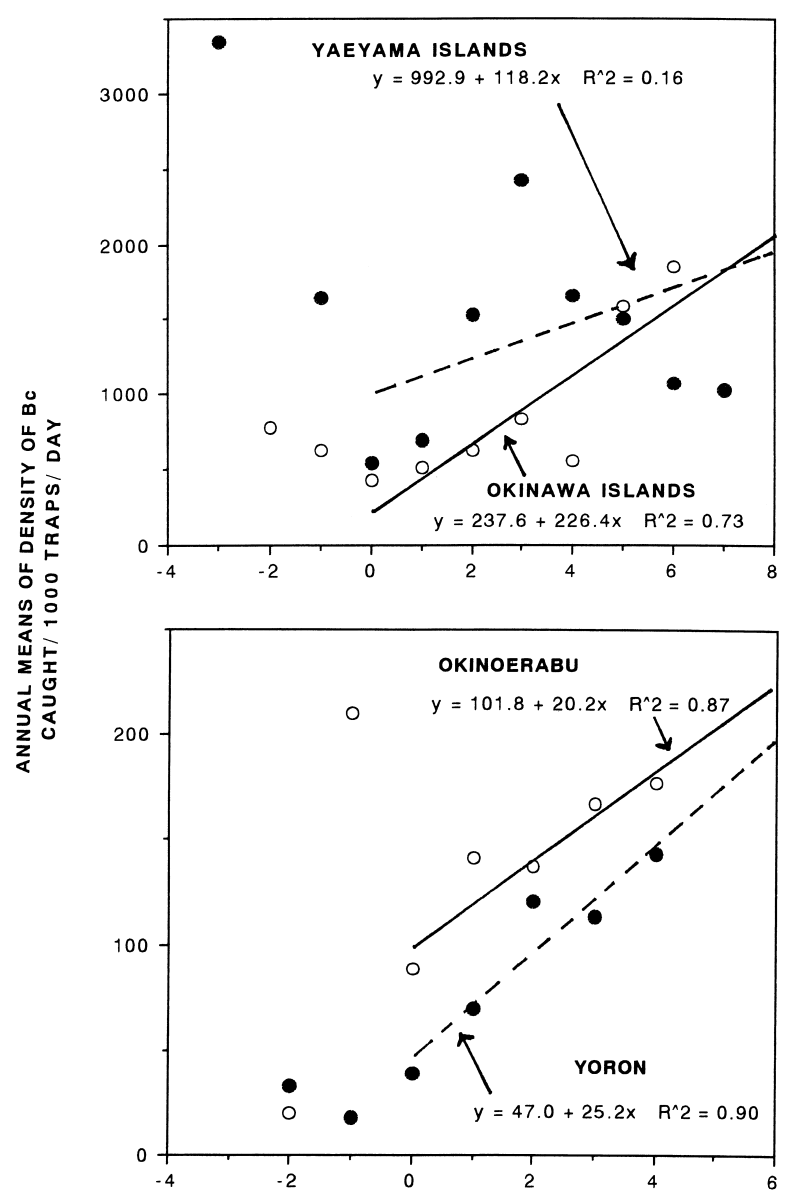

NUMBER OF YEARS BEFORE AND AFTER ERADICATION OF Bd

Fig. 3. Changes in annual mean density of B. cucurbitae, before and after eradication of $B$. dorsalis. For the calculation of linear regression, only values after Year 0 , year of the eradication of $B$. dorsalis were used. Top: Okinawa (open circles and solid line) and Yaeyama Islands (closed circles and broken line). Bottom: Okinoerabu-Zima (open circles and solid line) and Yoron-Zima (closed circles and broken line) in the Amami Islands.

Yoron, although density changes on OkinoerabuZima and Yoron-Zima might be influenced by the fact that $\mathrm{Bc}$ was introduced into these islands only $3 \mathrm{yr}$ before the eradication of $\mathrm{Bd}$ ). Correlation was not significant for the data of the Yaeyama Islands.

On Kume-Zima, counting of Bd flies started in April, 1977, the year following the eradication of Bc (although the Ministry of Agriculture and Fishery, Japan announced eradication in 1977, the percentage of infected host fruits became zero after October 1976), and aerial distribution of MEstrings began in October 1977. Figure 4 shows the number of Bd flies caught per 1,000 ME-traps/d on Kume-Zima, compared with data for other islands

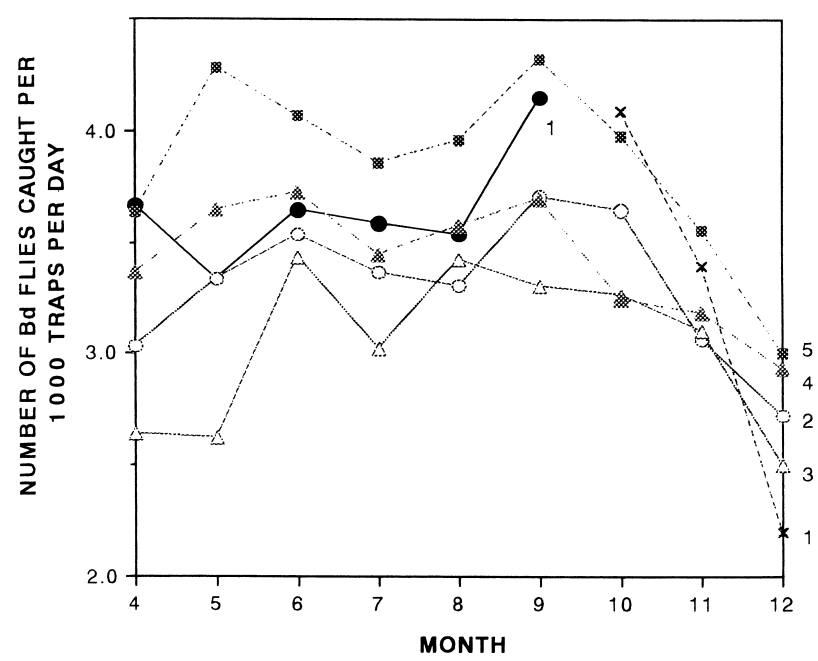

Fig. 4. Density trend of Bactrocera dorsalis (Bd) on Kume-Zima, after the eradication of B. cucurbitae (1, 1977; For a comparison, see the period shown by solid circles; period shown by cross marks is after beginning the eradication project of $\mathrm{Bd})$, compared with those on Okinawa Island (2, hollow circles, 1977), Miyako Island (3, white triangles, 1980 and 4, shaded triangles, 1981), and Yaeyama Island (5, squares, 1980).

where the Bc-eradication project had not yet started. Although a direct comparison cannot be made as the density trend might be different between years and islands (see Fig. 1), the trend of Bd density on Kume-Zima during the period between April and September, 1977 (shown by solid circles) seems to be not very different from trends on the other islands.

These results suggest that the interspecific competition between $\mathrm{Bd}$ and $\mathrm{Bc}$ might lead to an increase of $\mathrm{Bc}$ after the eradication of $\mathrm{Bd}$. However, if the competition effect exists, its influence is considered to be not so strong, because a remarkably high density was sometimes seen in years before the eradication (see Bc density on Yaeyama Islands in Year -3 , and that in Okinoerabu-Zima in Year -1 of Fig. 3, and high winter density the $2 \mathrm{yr}$ before the eradication of $\mathrm{Bd}$ on the Okinawa Islands shown in Fig. 1). Successful eradication of Bc several years after the eradication of $\mathrm{Bd}$ from all island groups of the Ryukyu Archipelago (see Itô et al., 2003) seems to support this opinion. Of course, much more data are necessary to know interspecific relations between the two species more accurately.

I think that the eradication of a species in areas where Bactrocera cucurbitae and B. dorsalis coex- 
ist can be conducted without large risk of notable increases in remaining species, but careful examination of density trends of other species is necessary. This method may be applied to other coexisting introduced pest species, such as the sweet potato weevils, Cylas formicarius and Euceps postfasciatus, in the Ryukyu Archipelago. As both species attack the same host plants (Convolvulaceae), the effect of the interspecific competition is expected to be stronger than that between $\mathrm{Bd}$ and Bc. However, in spite of nearly complete eradication of Cylas formicarius by a combination of the male annihilation method using sex pheromone and sterile insect release from Kume-Zima in 2003 (Kohama and Yamagishi, 2003; Okinawa-ken, 2003), there has been no indication of an increase in E. postfaciatus until the beginning of 2005.

\section{ACKNOWLEDGEMENTS}

I thank Drs. M. Yamagishi, T. Kohama and A. Tanaka for checking original tables of fruit fly numbers during the eradication projects in Okinawa and Kagoshima prefectures, and Dr. P. Spradbery for valuable comments on an earlier draft of the manuscript. I also thank two anonymous reviewers for their helpful comments on the manuscript.

\section{REFERENCES}

Christensen, L. D. and D. H. Foote (1960) Biology of fruit lies. Ann. Rev. Entomol. 5: 171-192.

Itô, Y., H. Kakinohana, M. Yamagishi and T. Kohama (2003) Eradication of the melon fly, Bactrocera cucurbitae, from Okinawa, Japan, by means of the sterile insect technique, with special emphasis on the role of basic studies. $J$.
Asia-Pacific Entomol. 6: 119-129.

Itô, Y. and J. Koyama (1982) Eradication of the melon fly: Role of population ecology in the successful implementation of the sterile insect release method. Prot. Ecol. 4: $1-28$.

Iwahashi, O., Y. Itô and S. Koba (1976) Problems around fruit flies in Japan, II. On an experimental project to eradicate the melon fly from Kume Island and on the Oriental fruit fly in Amami Islands. Kagaku 46: 436-444 (in Japanese).

Kohama, T. and M. Yamagishi (2003) Progress of the eradication program of the sweetpotato weevil, Cylas formicarius (Fabicius) (Coleoptera: Brentidae), using both of sex-pheromone and sterile insect technique in Kume Island, Okinawa, Japan. In Korea-Japan Joint Conference on Applied Entomology and Zoology, 2003, pp. 14-15.

Nakamori, H. and H. Soemori (1981) Attractiveness of methyl eugenol to the Oriental fruit fly, Dacus dorsalis Hendel, applied with various absorbents. Bull. Okinawa Agric. Exp. Stn. 6: 47-51 (in Japanese with English summary).

Okinawa-ken (2003) Eradication Project of the Sweetpotato Weevil, Cylas formicarius, on Kume-Zima. Report for Conference on Special Insects and Diseases of Crops, 17 June, 2003. Division of Agriculture and Forestry, Okinawa Prefectural Government, Naha. 17 pp. (in Japanese).

Strong, D. R. (1982) Harmonious coexistence of hispine beetles on Heliconia in experimental and natural communities. Ecology 63: 1039-1049.

Strong, D. R., J. H. Lawton and R. Southwood (1984) Insects on Plants: Community Patterns and Mechanisms. Blackwell, Oxford. 313 pp.

Ushio, S. (1981) A List of Host Plants of the Oriental Fruit Fly and the Melon Fly (Mimeographed Report). Plant Quarantine Office, Ministry of Agriculture, Yokohama, Japan. 20 pp. (in Japanese). 